Jpn Circ J 1997; 61: 19-24

\title{
Prediction of Outcome of Electrical Cardioversion by Left Atrial Appendage Flow Velocities in Atrial Fibrillation
}

\author{
Kazuaki Tanabe, MD; Hiroyuki Yoshitomi, MD; Toshihiko Asanuma, MD; \\ Seiji Okada, MD; Toshio Shimada, MD; Shigefumi Morioka, MD
}

\begin{abstract}
We evaluated the usefulness of left atrial appendage (LAA) flow velocity during atrial fibrillation as an objective measure for prediction of the outcome of electrical cardioversion. Left atrial appendage peak velocities were measured by transesophageal echocardiography before cardioversion in 56 patients. Left atrial thrombus was demonstrated in $6(11 \%)$ of these patients. Cardioversion was then performed in the 50 patients who did not have a thrombus and in 1 patient whose left atrial thrombus disappeared after anticoagulant therapy $(\mathrm{n}=51)$. Thirty-eight patients converted to sinus rhythm which remained stable until discharge (initial success group). Of these, long-term ( $>6$ months) maintenance of sinus rhythm was achieved in 31 patients $(82 \%)$. Five patients with almost no detectable appendage contractions during atrial fibrillation were classified in the initial failure group. The peak LAA flow velocity was significantly higher in patients in the initial success group compared with the patients in the initial failure group $(25.6 \pm 12.0 \mathrm{vs} 15.3 \pm 10.7 \mathrm{~cm} / \mathrm{s}$, respectively; $\mathrm{p}<0.01)$. Left atrial appendage flow velocity during atrial fibrillation may be useful for identifying candidates for electrical cardioversion.
\end{abstract}

(Jpn Circ J 1997; 61: 19-24)

Key Words: Appendage; Atrial fibrillation; Cardioversion; Transesophageal echocardiography

A trial fibrillation is associated with a high risk of systemic embolism and, if there is any likelihood of success, an attempt should be made to restore sinus rhythm. Clinically useful predictors for successful cardioversion and the maintenance of sinus rhythm after successful cardioversion have not been definitively established. Some studies have attempted to predict initial or long-term success of cardioversion based on left atrial size ${ }^{1-4}$ the duration of atrial fibrillation ${ }^{5-7}$ or the etiology of atrial fibrillation, but the clinical usefulness of these predictors is controversial, and an objective and measurable laboratory test is needed. Measurement of left atrial appendage (LAA) flow provides information about emptying and filling of the LAA? Recent studies suggest that a very low LAA flow profile indicates a dysfunctional LAA? ${ }^{\text {-16 }}$ These findings indicate that LAA flow velocity measured by pulsed Doppler echocardiography reflects the mechanical activity of the LAA during atrial fibrillation. The purpose of this study was to assess the usefulness of LAA flow velocity during atrial fibrillation as a predictor of the outcome of cardioversion in patients with atrial fibrillation.

\section{Methods}

\section{Patient Population}

We performed transesophageal echocardiography (TEE) in 56 patients ( 34 men and 22 women) with atrial fibrillation who were consecutively referred for cardioversion. The ages of the patients ranged from 31 to 79 years (mean, 62 years). Underlying diseases included dilated cardiomyopathy in 12 patients, hypertrophic cardiomyopathy in 2 , hypertension in 6 , mild mitral stenosis (mitral valve area $>1.5 \mathrm{~cm}^{2}$ ) in 9 , moderate mitral regurgitation in 5 , aortic regurgitation in 1 and coronary artery disease in 5 . No apparent predisposing conditions were found in the other 16 


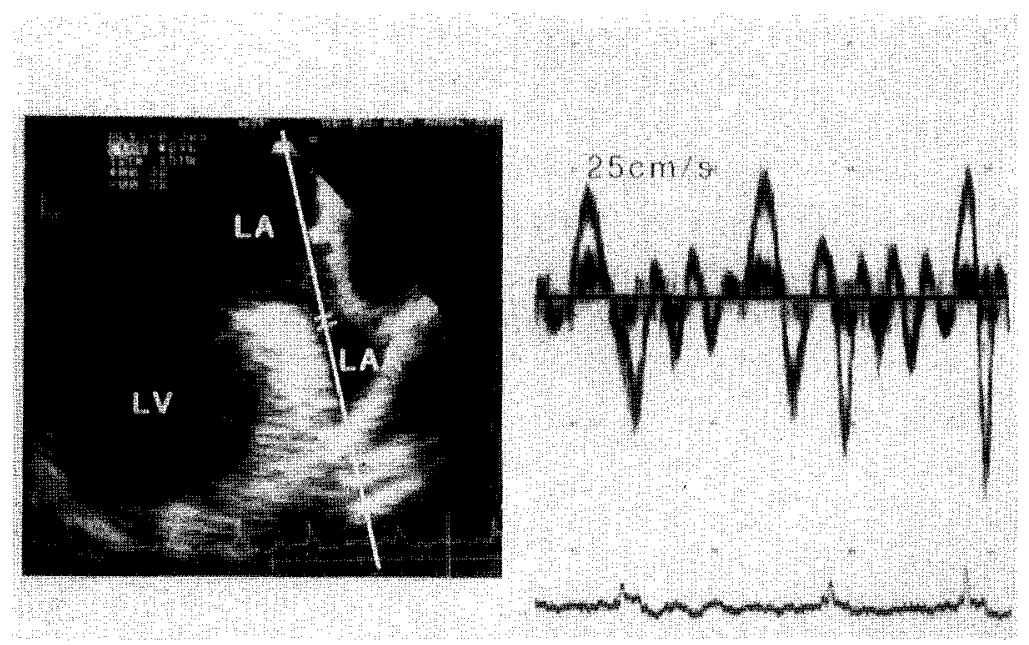

Fig 1. Pulsed wave Doppler recording of the left atrial appendage before cardioversion showing a fibrillatory flow pattern. LA: left atrium, LV: left ventricle.

patients. The clinically estimated duration of atrial fibrillation was $9.0 \pm 10.8$ months (range, 7 days to 60 months). Informed consent was obtained from all patients.

\section{Echocardiography}

After standard transthoracic M-mode, 2-dimensional and Doppler echocardiographic studies had been performed, TEE was performed within $24 \mathrm{~h}$ before cardioversion using a commercially available device (Aloka SSD 870, Tokyo, Japan) equipped with a $5-\mathrm{MHz}$ phased array bi-plane transducer. The oropharynx was anesthetized with a topical lidocaine spray and a viscous lidocaine solution. Patients were positioned in the left lateral decubitus position and then sedated with $5 \mathrm{mg}$ of diazepam administered intravenously before the probe was inserted. The left atrium and LAA were assessed for the presence or absence of spontaneous echo-contrast and thrombus. The LAA was viewed from the basal short axis, with the tip of the probe flexed slightly to permit observation of the whole length and width of the LAA. The Doppler sample volume was placed 1 to $2 \mathrm{~cm}$ into the orifice of the LAA to obtain the peak LAA velocity (Fig 1). The Doppler signals were recorded during 5 consecutive cardiac cycles on a strip chart recorder at $50 \mathrm{~mm} / \mathrm{s}$.

\section{Echocardiographic Data Analysis}

Atrial thrombus was diagnosed by the presence of a clearly defined intracavitary mass that was acoustically distinct from the underlying endocardium and was not related to the pectinate ridges of the $\mathrm{LAA}^{17}$ Spontaneous echo-contrast was diagnosed by the presence of dynamic, smoke-like echoes with a characteristic swirling motion, distinct from echoes caused by excessive gain ${ }^{18,19}$

We measured LAA peak emptying and filling fibrillatory velocities. The peak velocities within each $\mathrm{R}-\mathrm{R}$ interval were averaged in 5 consecutive cardiac cycles. Because filling velocities were generally equal in magnitude to the emptying velocities that preceded them, data are reported solely in terms of emptying velocities. The maximal LAA areas were measured in both planes by tracing a line starting from the top of the limbs of the left upper pulmonary vein along the whole appendage endocardial border? The left atrial and left ventricular end-diastolic and end-systolic dimensions were derived from 2-dimensional directed M-mode echocardiography obtained in the parasternal short-axis view.

\section{Cardioversion}

Anticoagulant therapy with warfarin was started at least 1 week before cardioversion. Digitalis was withheld before the procedure. In addition, treatment with disopyramide $(300 \mathrm{mg} / \mathrm{day})$ in 33 patients and flecainide $(150 \mathrm{mg} /$ day $)$ in 6 patients was started a few days before cardioversion. All other drugs (calcium antagonists, $\beta$-blockers or diuretics) were continued. A 12-lead electrocardiogram was recorded to determine the mean amplitude of the fibrillation waves in lead $V_{1}$. For cardioversion, we used a Nihon-Koden TEC-3500 defibrillator capable of a capacitor discharge of $350 \mathrm{~J}$. Cardioversion was performed in the coronary care unit after patients were sedated with intravenous thiopental sodium using the anterolateral paddle positions. Synchronized DC shocks were administered with increasing discharge energy until cardioversion was successful or a maximum of $350 \mathrm{~J}$ had been deliv- 
ered. Initial success of cardioversion was defined as the persistence of sinus rhythm until discharge from the hospital. The patients were examined by 1 of the authors and a 12 lead electrocardiogram was obtained at 6 months of follow up or if the patients experienced symptoms suggestive of recurrent atrial fibrillation.

\section{Statistical Methods}

All data are expressed as mean value \pm SD. Statistical comparison was performed by using the unpaired Student's t-test. Stepwise logistic regression analysis was performed to assess the relationship of variables to cardioversion using the StatView statistical package (version 4.1). A p value $<0.05$ was considered statistically significant.

Table 1 Comparison of Patients in the Initial Success Group and in the Initial Failure Group

\begin{tabular}{|c|c|c|c|}
\hline & Success & Failure & $p$ Value \\
\hline Number of patients & 38 & 13 & \\
\hline Age (years) & $62 \pm 11$ & $63 \pm 10$ & $N S$ \\
\hline Male/Female ratio & $22 / 15$ & $9 / 5$ & $N S$ \\
\hline Af duration (months) & $8.0 \pm 11.0$ & $12.6 \pm 10.0$ & $N S$ \\
\hline Valvular disease & $7(19 \%)$ & $3(21 \%)$ & $N S$ \\
\hline$V_{1} f$-wave $(\mathrm{mm})$ & $1.6 \pm 0.9$ & $1.1 \pm 0.8$ & $N S$ \\
\hline LA size $(\mathrm{mm})$ & $43 \pm 9$ & $47 \pm 8$ & $N S$ \\
\hline$L V D d(\mathrm{~mm})$ & $53 \pm 9$ & $56 \pm 13$ & $N S$ \\
\hline$F S(\%)$ & $29.5 \pm 8.5$ & $27.7 \pm 10.2$ & $N S$ \\
\hline LA smoke & $18 \quad(49 \%)$ & $11 \quad(79 \%)$ & $N S$ \\
\hline$L A A$ velocity $(\mathrm{cm} / \mathrm{s})$ & $25.6 \pm 12.0$ & $15.3 \pm 10.7$ & $<0.01$ \\
\hline$L A A$ area $\left(\mathrm{cm}^{2}\right)$ & $7.7 \pm 3.2$ & $7.1 \pm 2.4$ & $N S$ \\
\hline
\end{tabular}

Af $=$ Atrial fibrillation; $V_{1} f$-wave $=$ mean amplitude of fibrillation wave in $V_{1}$ lead of electrocardiogram; $L A=$ left atrium; $L V D d=$ left ventricular diastolic dimension; $F S=$ fractional shortening; $L A A=$ left atrial appendage

\section{Results}

\section{Initial Outcome of Cardioversion}

Transesophageal echocardiography demonstrated atrial thrombi in $6(11 \%)$ of the 56 patients. All thrombi were in the LAA. Therefore, cardioversion was performed in the remaining 50 patients who did not have thrombi and 1 patient whose LAA thrombus disappeared after anticoagulant therapy. Successful cardioversion, which remained stable until discharge ( $7 \pm 5$ days), was achieved in 38 (75\%, initial success group) of the 51 patients (Table 1). Left atrial appendage flow recordings from a patient in the initial success group and 2 patients in the initial failure group are shown in Fig 2. The peak LAA flow velocities during atrial fibrillation were significantly higher in the initial success group compared with those in the failure group $(\mathrm{p}<0.01$; Table 1, Fig 3). A stepwise logistic regression analysis was performed for the initial success of cardioversion using the variables listed in Table 1. Only peak LAA flow velocity was shown to be a significant predictor for cardioversion $(\mathrm{p}<0.01)$.

Peak LAA flow velocities $\geq 20 \mathrm{~cm} / \mathrm{s}$ had an initial success rate of $89 \%$. In contrast, peak LAA flow velocities $<20 \mathrm{~cm} / \mathrm{s}$ had an initial success rate of only $58 \%$. In 5 patients no detectable fibrillatory contractions of the appendage wall were noted (Fig 2C); all of these patients were in the initial failure group.

\section{Follow-up: Reversion to Atrial Fibrillation}

Seven $(18 \%)$ of 38 patients reverted to atrial fibrillation. There was no difference in duration of atrial fibrillation, left atrial size or patient age between these patients and patients who did not revert (Table 2). There was no difference in peak LAA flow velocity between patients with sustained sinus rhythm $(25.6 \pm 12.4$ $\mathrm{cm} / \mathrm{s}$ ) and patients who reverted to atrial fibrillation

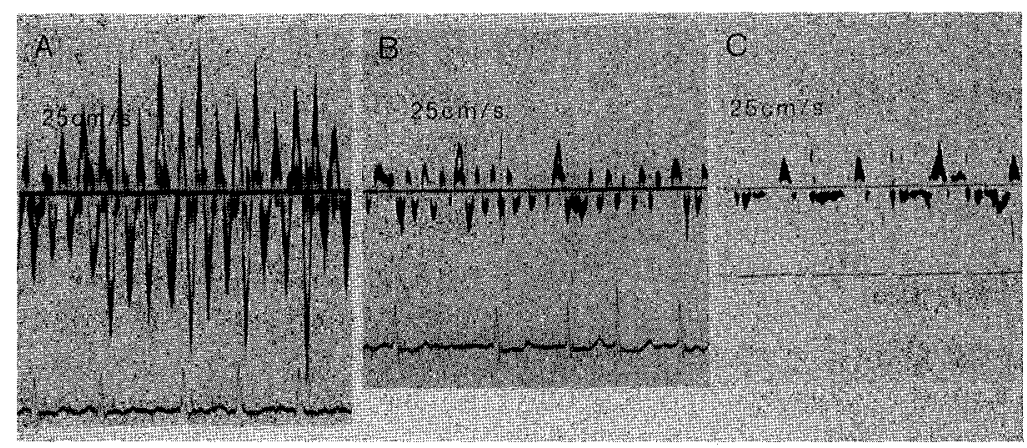

Fig 2. Pulsed wave Doppler recording of the left atrial appendage velocities during atrial fibrillation in a patient with successful cardioversion $(A)$ and 2 patients with unsuccessful cardioversion $(B, C)$. In panel $C$, there is passive filling flow during ventricular systole and passive emptying flow during ventricular diastole, with significantly low flow velocities. 


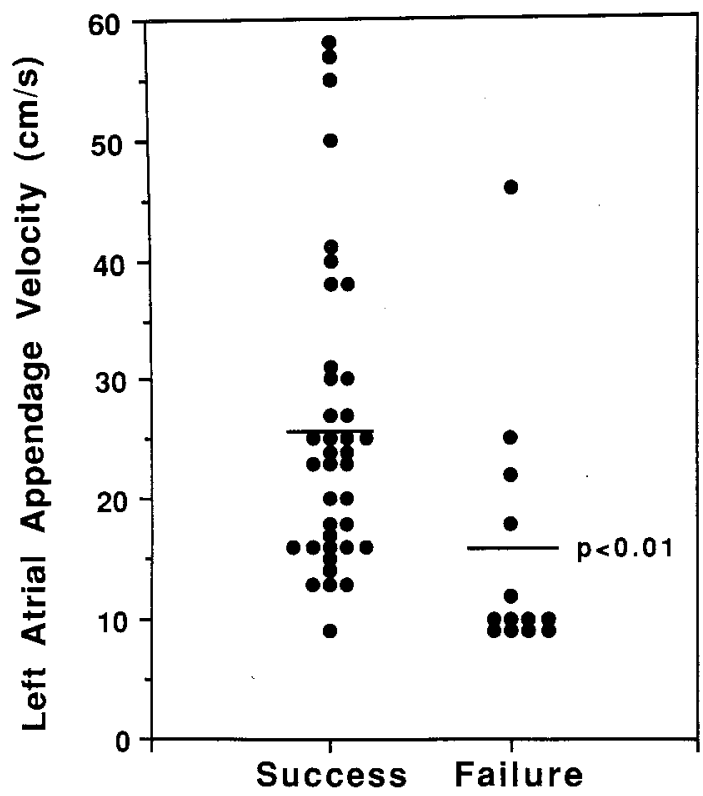

Fig 3. Left atrial appendage velocities in patients in the initial success group versus patients in the initial failure group.

Table 2 Comparison of Patients in the Long-Term ( $>6$ months) Success Group and in the Long-Term Failure Group

\begin{tabular}{|c|c|c|c|}
\hline & Success & Failure & $p$ Value \\
\hline Number of patients & 31 & 7 & \\
\hline Age (years) & $63 \pm 10$ & $54 \pm 13$ & $N S$ \\
\hline Male/Female ratio & $17 / 13$ & $2 / 5$ & $N S$ \\
\hline Af duration (months) & $7.0 \pm 12.0$ & $13.0 \pm 9.5$ & $N S$ \\
\hline Valvular disease & $5 \quad(17 \%)$ & $2(29 \%)$ & $N S$ \\
\hline$V_{1} f$-wave $(\mathrm{mm})$ & $1.6 \pm 0.9$ & $1.5 \pm 0.6$ & $N S$ \\
\hline$L A$ size $(\mathrm{mm})$ & $44 \pm 10$ & $40 \pm 10$ & NS \\
\hline$L V D d(m m)$ & $55 \pm 9$ & $49 \pm 6$ & $N S$ \\
\hline FS $(\%)$ & $27.4 \pm 8.6$ & $32.3 \pm 7.2$ & $N S$ \\
\hline LA smoke & $15 \quad(50 \%)$ & $3(43 \%)$ & $N S$ \\
\hline$L A A$ velocity $(\mathrm{cm} / \mathrm{s})$ & $25.6 \pm 12.0$ & $27.9 \pm 13.5$ & $N S$ \\
\hline$L A A$ area $\left(\mathrm{cm}^{2}\right)$ & $8.0 \pm 3.2$ & $7.0 \pm 2.9$ & $N S$ \\
\hline
\end{tabular}

Abbreviations are the same as for Table 1

$(27.9 \pm 13.4 \mathrm{~cm} / \mathrm{s})$

\section{Discussion}

The prevalence of atrial fibrillation increases with age $2^{20-22}$ Atrial fibrillation is associated with a high risk of systemic embolism and, if there is a likelihood of success, an attempt should be made to restore sinus rhythm. In the present study, we used the recently described variable, LAA function, to predict the outcome of cardioversion in patients with atrial fibrilla- tion. We observed lower LAA peak flow velocities in patients who remained in atrial fibrillation compared with patients in whom sinus rhythm was restored.

Patients with atrial fibrillation show 2 distinct LAA flow patterns: either well-defined emptying and filling flow velocity with visible fibrillatory contractions of LAA or very low LAA velocity with almost no detectable appendage contractions. In the latter subgroup, LAA seems to act like a static pouch in which emptying and filling occur passively. Previous investigators reported that a low LAA flow velocity was correlated with the presence of LAA thrombus in patients with atrial fibrillation and patients with sinus rhythm., 10 In general, it is difficult to assess the mechanical activity of the left atrium during atrial fibrillation. The left atrium does not generate detectable flow velocities during atrial fibrillation, as demonstrated by Doppler assessment of mitral inflow in sinus rhythm. However, the LAA is smaller than the left atrium and can generate greater flows than the left atrial cavity with the same contractile force. The LAA flow velocities may reflect the mechanical activity of both left atrium and appendage. The functional state of the left atrium can be determined before cardioversion. A high level of left atrial mechanical function during atrial fibrillation seems to indicate that the arrhythmia is potential reversible.

Previous studies have attempted to predict the initial or long-term success of cardioversion based on various clinical or laboratory features, including left atrial size, ${ }^{1-4}$ duration of atrial fibrillation ${ }^{5-7}$ and etiology of atrial fibrillation, 6.8 The ability of left atrial size to predict the success of cardioversion has been assessed in several studies! ${ }^{-4}$ Henry et al suggested that a left atrial dimension $>45 \mathrm{~mm}$ is unlikely to maintain sinus rhythm. In contrast, Dittrich et al reported that left atrial size did not appear to influence the outcome of cardioversion strongly? In the present study, left atrial size and left ventricular diastolic dimension tended to be larger in patients in whom cardioversion failed, although there were no statistically significant differences. The differences of results among these prior studies and the present study may be attributable to different patient populations and patient selection criteria, differences in the type of pharmacological therapy used after cardioversion and variable durations of follow-up.

Some investigators have suggested that patients are unlikely to maintain sinus rhythm if atrial fibrillation has been present more than 1 year, ${ }^{1,2}$ However, LÉvy et al found that the duration of atrial fibrillation was not significantly associated with the outcome of cardioversion ${ }^{23}$ which is consistent with the present 
findings. We did not find significant differences in the etiology and chronicity of atrial fibrillation between the success and failure groups. Recently, Mügge et al have demonstrated that peak LAA velocity is significantly lower in patients with chronic atrial fibrillation and rheumatic atrial fibrillation compared to patients with non-rheumatic atrial fibrillation ${ }^{15}$ It appears reasonable to assume that the LAA function is dependent on duration and the underlying cause of atrial fibrillation. However, the true duration of atrial fibrillation may not be correct if it is assessed on the basis of symptomatic episodes or electrocardiographic testing. The level of LAA mechanical function seems to be a more useful, measurable predictor of successful cardioversion.

Lown reported that the size of fibrillation waves in lead $V_{1}$ provides an important clue to energy requirements and the likelihood of the success of cardioversion. ${ }^{24}$ However, we did not observe a relationship between LAA velocities and the mean amplitude of fibrillation waves in lead $V_{1}$. Although LAA emptying flow correlates precisely with atrial mechanical activity ${ }^{25}$ it has been shown that there is no correlation between $\mathrm{f}$-wave amplitude in atrial fibrillation-flutter and LAA function? ${ }^{26}$

\section{Limitations}

We did not find significant differences in the etiology and chronicity of atrial fibrillation, left atrial size and left ventricular function between the initial success and initial failure groups. However, the small number of patients in the present study may limit the conclusions that can be drawn from our data. There was no association between the LAA function and the maintenance of sinus rhythm during the follow-up period. These results indicate that we cannot successfully predict long-term ( $>6$ months) maintenance of sinus rhythm by simply referring to the LAA function before cardioversion. This may be because a patient who develops atrial fibrillation in response to myocardial ischemia is likely to revert to atrial fibrillation when ischemia reoccurs, regardless of high left atrial appendage velocity before cardioversion. In addition, maintenance of sinus rhythm is influenced by antiarrythmic drug therapy. The introduction of newer antiarrhythmic drugs may affect the likelihood of recurrence of atrial fibrillation. ${ }^{27-29}$ The influence of this variable could not be fully assessed in the present study.

\section{Conclusions}

The present study suggests a significant relationship between LAA flow velocity and the likelihood of success of cardioversion of patients with atrial fibrillation. In particular, the results suggest that patients with passive filling and emptying flow in the LAA are unlikely to maintain sinus rhythm after electrical cardioversion. These findings have important implications for the management of patients with atrial fibrillation.

\section{References}

1. Henry WL, Morganroth J, Pearlman AS, Clark CE, Redwood DR, Itscoitz SB et al: Relation between echocardiographically determined left atrial size and atrial fibrillation. Circulation 1976; 53: 273-279

2. Halpern S, Ellrodt G, Singh B, Mandel W: Efficacy of intravenous procainamide infusion in converting atrial fibrillation to sinus rhythm: relation to left atrial size. $\mathrm{Br}$ Heart J 1980; 44: 589-595

3. Ewy GA, Ulfers L, Hager WD, Rosenfeld AR, Roeske WR, Goldman S: Response of atrial fibrillation to therapy: role of etiology and left atrial diameter. $J$ Electrocardiol 1980; 13: $119-124$

4. Brodsky MA, Allen BJ, Capparelli EV, Luckett CR, Morton R, Henry WL: Factors determining maintenance of sinus rhythm after chronic atrial fibrillation with left atrial dilatation. Am J Cardiol 1989; 63: 1065-1068

5. Szekely P, Sideris DA, Batson GA: Maintenance of sinus rhythm after atrial defibrillation. Br Heart $J$ 1970; 32: $741-746$

6. Flugelman MY, Hasin Y, Katznelson N, Kriwisky M, Shefer A, Gotsman MS: Restoration and maintenance of sinus rhythm after mitral valve surgery for mitral stenosis. $A m J$ Cardiol 1984; 54: 617-619

7. Dittrich HC, Erickson JS, Schneiderman T, Blacky A, Savides T, Nicod PH: Echocardiographic and clinical predictors for outcome of elective cardioversion of atrial fibrillation. Am J Cardiol 1989; 63: 193-197

8. Morris JJ Jr, Peter RR, McIntosh HD: Electrical conversion of atrial fibrillation. Ann Intern Med 1966; 65: $216-231$

9. Pollick C, Taylor D: Assessment of left atrial appendage function by transesophageal echocardiography: implications for the development of thrombus. Circulation 1991; 84: 223-231

10. Pozzoli M, Febo O, Torbicki A, Tramarin R, Calsamiglia $\mathrm{G}$, Cobelli et al: Left atrial appendage dysfunction: a cause of thrombosis? Evidence by transesophageal echocardiography-Doppler studies. I Am Soc Echocardiogr 1991; 4: 435-441

11. Garcia-Fernandez MA, Torrecilla EG, Roman D, Azevedo $J$, Bueno $H$, Moreno $M$ et al: Left atrial appendage Doppler flow patterns: implications on thrombus formation. Am Heart J 1992; 124: 955-961

12. Matsuzaki M, Toma Y, Kusukawa R: Clinical application of transesophageal echocardiography. Circulation 1990; 82: $709-722$

13. Verhorst PMJ, Kamp O, Visser CA, Verheugt FWA: Left atrial appendage flow velocity assessment using transesophageal echocardiography in nonrheumatic atrial 
fibrillation and systemic embolism. Am J Cardiol 1993; 71: 192-196

14. Grimm RA, Stewart WJ, Maloney JD, Cohen GI, Pearce GL, Salcedo EE et al: Impact of electrical cardioversion for atrial fibrillation on left atrial appendage function and spontaneous echo contrast: characterization by simultaneous transesophageal echocardiography. J Am Coll Cardiol 1993; 22: $1359-1366$

15. Mügge A, Kühn H, Nikutta P, Grote J, Lopez JAG, Daniel WG: Assessment of left atrial appendage function by biplane transesophageal echocardiography in patients with nonrheumatic atrial fibrillation: identification of a subgroup of patients at increased embolic risk. J Am Coll Cardiol 1994; 23: 599-607

16. Fatkin D, Kelly RP, Feneley MP: Relations between left atrial appendage blood flow velocity, spontaneous echocardiographic contrast and thromboembolic risk in vivo. $J \mathrm{Am}$ Coll Cardiol 1994; 23: $961-969$

17. Beppu S, Park YD, Sakakibara H, Nagata S, Nimura Y: Clinical features of intracardiac thrombosis based on echocardiographic observation. Jpn Circ J 1984; 48: 75-82

18. Beppu S, Nimura Y, Sakakibara H, Nagata S, Park YD, Izumi S: Smoke-like echo in the left atrial cavity in mitral valve disease: its features and significance. $J$ Am Coll Cardiol 1985; 6: 744-749

19. Daniel WG, Nellessen U, Schröder E, Nonnast-Daniel B, Bednarski $P$, Nikutta $P$ et al: Left atrial spontaneous echo contrast in mitral valve disease: an indicator for an increased thromboembolic risk. J Am Coll Cardiol 1988; 11: $1204-1211$

20. Britton M, Gustafsson C: Non-rheumatic atrial fibrillation as a risk factor for stroke. Stroke 1985; 16: 182-188

21. Brand FN, Abbot RD, Kannel WB, Wolf PA: Characteris- tics and prognosis of lone atrial fibrillation. JAMA 1985; 254: $3449-3453$

22. Cairns JA, Connolly SJ: Nonrheumatic atrial fibrillation. Risk of stroke and role of antithrombotic therapy. Circulation 1991; 84: 469-481

23. LÉvy S, Lauribe P, Dolla E, Kou W, Kadish A, Calkins H et al: A randomized comparison of external and internal cardioversion of chronic atrial fibrillation. Circulation 1992; 86: $1415-1420$

24. Lown B: Electrical reversion of cardiac arrhythmias. $\mathrm{Br}$ Heart $J$ 1967; 29: 469-489

25. Mitusch R, Garbe M, Schmücker G, Schwabe K, Stierle U, Sheikhzadeh A: Relation of left atrial appendage function to the duration and reversibility of nonvalvular atrial fibrillation. Am J Cardiol 1995; 75: 944-947

26. Santiago D, Warshofsky M, Li Mandri G, Di Tullio M, Coromilas J, Reiffel J et al: Left atrial appendage function and thrombus formation in atrial fibrillation-flutter: a transesophageal echocardiographic study. J Am Coll Cardiol 1994; 24: 159-164

27. Brodsky MA, Allen BJ, Walker CJ, Casey TP, Luckett CR, Henry WL: Amiodarone for maintenance of sinus rhythm after conversion of atrial fibrillation in the setting of a dilated atrium. Am J Cardiol 1987; 60: 572-575

28. Juul-Moller J, Edvardsson N, Rehnqvist-Ahlberg N: Sotalol versus quinidine for the maintenance of sinus rhythm after direct current conversion of atrial fibrillation. Circulation 1990; 82: 1932-1939

29. Antman EM, Beamer AD, Cantillon C, McGowan N, Friedman PL: Therapy of refractory symptomatic atrial fibrillation and atrial flutter; a staged care approach with new antiarrhythmic drugs. J Am Coll Cardiol 1990; 15: $698-707$ 